УДК 316.77

DOI https://doi.org/10.23947/2658-7165-2021-4-1-36-50

\title{
Социально-психологические функции комплимента в межличностном общении
}

\author{
Камидла О. Цахияова \\ Южный федеральный университет, г. Ростов-на-Дону, Российская Федерация \\ E-mail: cahilova@sfedu.ru \\ ORCID: https://orcid.org/0000-0001-9480-631X
}

\section{Аннотация}

В статье рассматривается комплимент как важный компонент межличностного общения. В разделе Ввеление автором раскрывается актуальность исследуемой темы в связи с проблемой установления и подАержания отношений межАу ^юАьми, их Аальнейшей гармонизацией, Аостижением эфрорективного бесконфликтного взаимодействия. В теоретическом обосновании автором привоАится обзор основных поАХоАОв к рассмотрению френомена комплимента в отечественных и зарубежных исслеАованиях; включая вопросы схоАства и различия комплимента, ^ести и похвалы; влияния комплиментов на качество и характер общения. Новизна исследования заключается в вылелении и систематизации фуннкцй комплиментов в межличностном общении, описании и структурировании их фрормально-солержательных характеристик, анализе соотношения со сходными речевыми высказываниями. Поскольку Аанное явление изучается также в ^ингвистике, это обуслови^о межАисциплинарный характер его рассмотрения: в русле социально-психологического и ^ингвистического знания. В разделе ОбсужАение результатов автором вылеляются основные направления исслеАования российских и иностранных авторов, которые позволяют говорить о важности комплиментов в межличностном взаимодействии. В заключении в качестве основных, наиболее важных, функций, которые выполняет комплимент, вылеляются такие, как: 1) установление и подлержание доброжелательных отношений или гармонизация межличностных отношений; 2) оказание эмоциональной полАержки; 3) соблюАение этикета; 4) Аоставление удовольствия собеседнику; 5) удовлетворение потребностей партнера в признании и одобрении; 6) конструктивная или созидательная (в конфликтном Аискурсе); 7) оказание психологического воздействия; 8) альтернатива Аругим речевым актам. Автором подчеркивается недостаточная изученность данной темы, намечаются Аальнейшие перспективы исследования. 


\title{
КАючевые слова
}

комп^имент, межличностное общение, похвала, лесть, комп^иментарные высказывания, психологическое воздействие, межличностные отношения

\section{Для цитирования}

Цахилова К. О. Социально-психологические функции комплимента в межличностном общении // Инновационная наука: психодогия, педагогика, дефектология. 2021. Т. 4, № 1. С. 36-50. doi: https://doi.org/10.23947/2658-7165-2021-4-1-36-50

\section{The social and psychological functions of a compliment in interpersonal communication}

\author{
Kamilla O. Tsakhilova \\ Southern Federal University, Rostov-on-Don, Russia \\ E-mail: cahilova@sfedu.ru \\ ORCID ID: https://orcid.org/0000-0001-9480-631X
}

\begin{abstract}
The article deals with a compliment as an important component of interpersonal communication. In the Introduction, the author reveals the relevance of the topic under study in connection with the problem of establishing and maintaining relations between people, their further harmonization, and achieving effective conflict-free interaction. In the theoretical substantiation, the author provides an overview of the main approaches to the consideration of the phenomenon of a compliment in Russian and foreign studies; including the issues of similarities and differences of a compliment, flattery, and praise; the influence of compliments on the quality and nature of communication. The novelty of the research lies in the identification and systematization of the functions of compliments in interpersonal communication, the description, and structuring of their formal and substantive characteristics, the analysis of the relationship with similar speech utterances. As this phenomenon is also studied in linguistics, the interdisciplinary approach to the consideration of compliment had a place to be: in the context of socio-psychological and linguistic knowledge. In the Discussion section, the author emphasizes the main areas of research of Russian and foreign authors, which allow us to talk about the importance of compliments in interpersonal interaction. In conclusion, the most important functions that a compliment performs are highlighted: 1) establishing and maintaining friendly relationships or harmonizing interpersonal relationships; 2) providing emotional support; 3) observing etiquette; 4) giving pleasure to the interlocutor; 5) meeting the partner's needs for recognition and approval; 6) constructive or creative (in a conflict discourse); 7) providing psychological
\end{abstract}


influence; 8) an alternative to other speech acts. The author emphasizes the lack of knowledge of this topic, outlines further prospects for research.

\section{Keywords}

compliment, interpersonal communication, praise, flattery, complimentary statements, psychological impact, interpersonal relationships

\section{For citation}

Tsakhilova, K. O. (2021). The social and psychological functions of a compliment in interpersonal communication. Innovative Science: psychology, pedagogy, defectology, 4(1), 36-50. doi: https://doi.org/10.23947/2658-7165-2021-4-1-36-50

\section{Введение}

Значимость умело составленных и «поданных» комплиментов высока, так как они открывают массу возможностей в раздичных сферах деятельности. К примеру, в профессиональной сфере комплименты позволяют продемонстрировать свою заинтересованность деловым партнером. Несмотря на то, что «комплиментарные» высказывания обычно содержат небодьшое преувеличение достоинств собеседника, умение дать человеку возможность почувствовать собственную ценность - позволяет быстрее получить желаемое. С помощью комплимента можно создать условия для плодотворного взаимодействия и в рабочем пространстве: положительно оценить проделанную работу коллег, признать ее полезность и важность. Помимо деловых, комплименты являются неотъемлемой частью и романтических отношений. По это причине особенно ярко выражено исподьзование компдиментов в общении мододых людей.

Исследованием проблемы вдияния комплиментов на междичностные отношения занимались такие психологи, как Р. Чалдини (2021), Д. Карнеги (2020), Ф. Зимбардо и М. Аяйппе (2001). Отдельные лингвистические аспекты изучадись О. С. Иссерс (2008) и другими. В то же время компдимент редко рассматривался как самостоятельный феномен, он всегда шел в сравнении и взаимосвязи с похвалой, ложью и лестью, не выделялись четко его социально-психологические функции.

Актуальность данного теоретического исследования обусловлена тем, что на сегодняшний день в отечественной психологической науке недостаточно, на наш взгляд, работ, посвященных проблеме «вклада» комплимента в установление и развитие межличностных отношений. В силу этого, не систематизированы социально-психологические функции комплимента, который является самым простым и удобным в использовании инструментом выстраивания полноправного диалога или манипулирования. Доставдяя удовольствие собеседнику и поднимая его настроение, он может выступать в качестве «рычага вдияния», способа 
достижения успешных результатов в междичностном общении, для всех, кто к этому стремится. В этой связи интерес представляет также и сравнительный анадиз сходных с компдиментом явлений и их социально-психологических функций, что задает междисциплинарный характер рассмотрения, объединяющий социадьно-психологические трактовки и дингвистический подход.

Таким образом цеель исследования - рассмотреть компдимент как вид психологического воздействия, сравнить его с лестью и похвалой и выдедить социально-психологические функции комплимента.

\section{Теоретическое обоснование}

Компдимент - самый распространенный в ситуациях повседневного межличностного взаимодействия речевой акт, выступающий ярким и востребованным проявлением подачи обратной связи: M. Cordella, H. Large, и V. Pardo, опираясь на исследования предшественников P. Brown and S. Levinson, уточняют, что это не просто выразительный речевой акт, а «позитивная стратегия веждивости» (positive politeness strategy), с помощью которой выражается восхищение каким-дибо благом или его одобрение (Cordella et al., 1995). С точки зрения практической психологии, с ее акцентом на деловое общение - компдимент есть необходимый компонент создания способствующей эффективности взаимодействия доверительной тонадьности.

Н. А. Коваль и Е. А. Захарова относят комплимент к числу психологических методов управления, которые «концентрируют все необходимые и разрешенные законом приемы воздействия на дюдей для координации в процессе совместной трудовой деятельности» (Коваль, Захарова, 2004, с. 37).

По мнению Д. А. Шевчука, комплимент является одним из условий успешного протекания делового общения, так как он позволяет увеличить шансы удачного разрешения проблем и закдючения сделок. Под ним автор понимает приятное слово, вкдючающее «небольшое преувеличение положительных качеств человека» (Шевчук, 2006, с. 57).

Согласно «стратегии поведения» Д. Карнеги предполагается, что компдименты следует составдять таким образом, чтобы они оценивали не внешние качества человека, а внутренние. Этим человек демонстрирует, что мыслит не поверхностными образами, а может усмотреть богатство внутреннего мира собеседника (Карнеги, 2020).

Поскольку феномен «комплимент» не редко являлся предметом исследования в работах, которые были посвящены проблемам межкультурной коммуникации и нормам речевого общения (Беляева-Станден, 2006; Дьякова, 2015; Иссерс, 2008; Шалюхина, 2017; Cordella et al., 1995), то, при анализе данного феномена, вполне уместен междисциплинарный подход, включающий социальную психологию и лингвистику. 
Примером такого подхода могут служить два психодингвистических эксперимента Е. И. Беляевой-Станден. Эмпирическим объектом исследования выступили студенты московских и воронежских вузов в возрасте от 18 до 30 яет. Целью исследования являлось определение общих представлений мужчин и женщин о своем поведении в ситуациях, в которых фигурировали компдименты. В частности, автора интересовали «частотность выражения и получения комплимента в зависимости от характеристик адресата (возрастная и психологическая дистанция), предмета/объекта компдимента, тип реакции на компдимент, а также понимание самого акта компдимента и мотивации его осуществления» (Беляева-Станден, 2006, с. 156).

Е. И. Беляева-Станден пришла к выводу, что комплимент «представляет собою положительное высказывание, в котором говорящий отмечает что-либо хорошее/позитивное в собеседнике с целью сделать ему приятное, показать ему своё расположение и тем самым расположить его к себе» (Беляева-Станден, 2006, с. 156). С помощью таких фраз у инициатора появляется возможность установить и поддерживать доброжелательные отношения.

На данный аспект также обращает внимание и J. G. Loor, допуская, что комплименты часто применяются из принципа вежливости в межличностном общении (Loor, 2020). Следовательно, полагает автор, можно предположить, что субъекты общения могут делать компдименты неосознанно, исподьзуя готовые, заранее составленные клишированные фразы, или наоборот - осознанно, преследуя какую-либо цель.

Y. Dai и соавторы, рассматривая проблему последствий раскрытия личной информации (реакций на нее) в информационном пространстве, выявили, что ответное самораскрытие и комплименты раскрывающемуся - это те реакции, которые повышают качество общения, «способствуют близости» (Dai et al., 2016, c. 397). Человек становится уязвимым, раскрывая значимую для себя информацию партнеру, поэтому, тот, в свою очередь, (для того, чтобы вызвать еще большее доверие) - может применить в своей речи компдименты, тем самым, выражая свою заинтересованность, и стимулируя рассказ собеседника о себе. Авторы обращают внимание на то, что в таких ситуациях комплименты можно считать способом выражения обратной связи. Кроме того, утверждают они, дюди думают о тех, кто дает им положительные отзывы, «как о более симпатичных, привлекательных, компетентных и умных» (Dai et al., 2016, с. 398). По этой причине, по мнению Y. Dai и соавторов, комплимент в большей степени оказывает вдияние на развитие симпатии в дюбой диаде, чем «взаимное самораскрытие».

«Структура» комплиментарного взаимодействия достаточна проста. Согласно О. С. Иссерс, он содержит три главных элемента: субъект компдимента, объект комплимента, и предмет, по причине которого делается комплимент (Иссерс, 2008). Однако, форма «реализации комплимента» обуславдивается 
прагматическим контекстом, в который входит социальная и психологическая дистанция между субъектами общения, а также место и время.

\section{Сравнительный анализ комплимента, лести и похваль}

Одним из важных моментов в исследовании компдимента как своеобразного явления, обладающего своей спецификой, явдяются попытки отделить его от сходных речевых высказываний. Исследования, посвященные анадизу комплиментов, можно разделить по двум направлениям: разграничивающие понятия «комплимент», «лесть» и «похвала» и объединяющие их в один вербальный акт. На наш взгляд, каждый из этих феноменов не повторяет предыдущий, они существует независимо друг от друга и имеют черты, по которым их можно раздичать.

Похвалу, как и комплимент, принимают за способ позитивного психологического воздействия. Ее противоположностью является «осуждение» (Loor, 2020). Похвала встречается не только в повседневной жизни. Н. А. Коваль и Е. А. Захарова в своей работе (Коваль и Захарова, 2004) утверждают, что похвала в деловом общении - не редкое явление, и ее используют старшие по возрасту либо по рангу, званию. В этом способе воздействия осуществляется «пристройка сверху» (позиция «над») (Шейнов, 2015). Именно поэтому полученная похвала может не доставдять удоводьствия.

Говоря о «компдиментарности» как о форме проявдения тактичности, Ю. А. Разинов утверждает, что «комплименты и похвалы лживы, но им все равно бывают рады» (Разинов, 2014, с. 20).

В. П. Шейнов, размышляя о специфике и эффективности комплиментов, находит их главное отличие от похвалы в том, что похвала - это всегда оценка, а комплимент - восхищение и удивление (Шейнов, 2015).

Аингвисты дифференцируют комплимент и похвалу по критерию цели высказывания: цель комплимента - сообщить о благорасположении, а цель похвалы - дать положительную оценку человеку (Иссерс, 2008).

Оказалась ли наша похвала успешной, мы определяем по реакции собеседника, вербальной или невербальной, иными словами, ждем принятия иди отклонения оценки. В случае комплимента, результат всегда положительный, даже если партнер не согласен с высказыванием. Если похвала предполагает оценку человека, его знаний и умений, то предметом комплимента, считают исследователи, являются «вещи, дела, идеи и так далее, косвенно относящиеся к людям», как пишут Н. А. Коваль и Е. А. Захарова (Коваль, Захарова, 2004, с. 39). При этом увеличивается спектр причин, по которым человеку можно сделать комплимент. Отделяя яесть от комплимента, Н. А. Коваль и Е. А. Захарова приводят следующее отличие: «Десть проста и понятна. Компдимент же наталкивает человека на размышления, на догадку» (Коваль, Захарова, 2004, с. 39). 
Дюди очень благоскдонно реагируют на лесть (Чалдини, 2021) несмотря на то, что тот, кто произносит ее, возвышает собеседника над ним самим, осуществляя «пристройку снизу». Десть, «фальшь которой сокрыта и неверифицируема», представляет собой более грубую форму обмена ложью, по мнению Ю. А. Разинова (Разинов, 2014, с. 20). Рассуждая о субъектах, в общении которых преобладает лесть, автор обращает внимание на то, что «лесть необходима не только иьстецу как «слабому», но и тщеславному как «сильному мира сего», причем не столько для «поглаживания» его эго (как в случае похвалы и комплимента), сколько для подтверждения начальственного статуса» (Разинов, 2014, с. 20).

Ф. Зимбардо и М. Аяйппе установиди, что такие приемы, как лесть и мелкие «добрые» поступки (предложить чашку кофе, стакан воды или сигарету) позволяют сделать так, чтобы одному человеку захотелось довериться другому (Зимбардо и Дяйппе, 2001). Десть - это угодливое восхваление каких-либо достоинств человека, преувеличивающее их реальную ценность, для извлечения выгоды. В большинстве случаев иьстят в адрес вышестоящего по положению или статусу, дьстят тому, от кого зависит субъект.

Таким образом, комплимент, похвала и лесть схожи в том, что несут положительную окраску. Однако только в комплиментах сохраняются равные позиции между субъектами общения. Цель комплимента - сообщить собеседнику нечто приятное о делах, поступках, восхититься его идеями, не затрагивая дичность и ее качества, чтобы наладить либо развить контакт с партнером. Приведем пример, который может служить высказыванием такого типа: «Ваша работа выгдядит очень достойно!» Цель похвалы - сообщить адресату о положительной оценке его и его качеств, выбрав «позицию над». Например, высказывание: «Сегодня ты молодец!». С целью преувеличения достоинств партнера инициатор избирает форму лести и позицию «под». Десть, в отличие от похвалы и компдимента, допускает не простое преувеличение качеств и умений, а обман или неискренность. Приведем пример: «Ты самая красивая девушка на свете!»

\section{Комплимент как психологическое воздействие}

В основе действия комплиментов, как утверждает $\Lambda$. Ф. Голубева, «лежит психологический феномен внушения» (Голубева, 2015, с. 71). Таким образом, если человек часто будет слышать, что его работа всегда выполнена качественно, его идеи всегда креативны, он поверит в это, а появившаяся потребность совершенствоваться в этом вопросе лучше будет удовлетворяться, что вызовет положительные эмоции и стимул к выполнению тех или иных поручений.

Ф. И. Карташкова, Н. Б. Мальцева и А. А. Князева считают, что комплимент стоит рассматривать в качестве манипулятивного приема (Карташкова и др., 2017). Также существуют версии, сторонники которых полагают, что компдимент входит в такой вид психодогического вдияния, как «формирование 
благосклонности» (Сидоренко, 2000; Loor, 2020), путем высказывания благоприятных суждений о человеке (Сидоренко, 2000; Саковская, 2017).

Наиболее полно, на наш взгляд, комплимент рассматривается в работе В. П. Шейнова. Он утверждает, что компдимент нельзя отнести к уже выделенным видам психологического воздействия, он независим от них и представдяет собой отдельный, автономный способ психодогического вдияния на партнера (Шейнов, 2015). Автор аргументирует свою позицию тем, что комплимент, как и другое осознаваемое воздействие, имеет универсальную структуру. В нее входят: сбор информации об адресате (это необходимо дия создания фактической основы компдимента, делающей его искренним); вовлечение в контакт путем активации положительных эмоций; фоновые факторы (состояние сознания собеседника, его функциональное состояние, привычные модели поведения в ответ на комплиментарные высказывания, а также факторы, связанные с доверием, высоким статусом и привлекательностью инициатора), мишени воздействия - основаны на удовлетворении актуальных потребностей партнера (потребность в одобрении, потребность в уважении и потребность в признании). Последний компонент в представленной В. П. Шейновым структуре - побуждение к активности, предполагающее, что за комплиментом должна последовать какая-то реакция.

Таким образом, на основе обзора теоретических исследований, нам представляется возможным рассматривать комплимент либо как разновидность, вариацию уже установленных видов психологического воздействия, либо как самостоятельный вид, имеющий свою собственную структуру и особенности.

\section{Социиально-психологические функции комплимента}

На основании теоретического анализа отечественных и зарубежных источников мы попытались выделить основные социально-психологические функции комплимента, систематизировав представления авторов о нем.

1) Установление и поддержание доброжелательных отношений или гармонизация межличностных отношений является одной из важнейших функций комплимента, по мнению таких авторов, как О. С. Иссерс (2008), А. В. Бартош и Е. А. Нечаева (2008), Е. М. Doohan и V. Manusov (2004), так как он направлен на урегулирование или укрепление отношений.

Если ваш комплимент оказался уместен, то это станет одним из шагов установления первоначального контакта с собеседником и создания позитивного настроя для дальнейшего развития вашей беседы. Таким образом, комплимент уменьшает социальную дистанцию между взаимодействующими (Doohan, Manusov, 2004).

2) Оказание эмоциональной поддержки также является функцией комплиментов. Проведенное эмпирическое исследование А. О. Ариповой и Т. А. Крюковой 
выявило предпочтения 196 респондентов по получаемым и оказываемым формам эмоциональной поддержки: «комплимент» высоко оценивался личностью как форма получения эмоциональной поддержки «в связи с укреплением веры в себя, в свои силы и развитие мотивации для разрешения сложившихся трудностей» (Арипова, Крюкова, 2019, с. 105). Авторы подчеркивают, что получение поддержки в такой форме ожидается в первую очередь от супруга.

3) Соблюдение этикета. Основой комплиментарных высказываний является желание проявить вежливость. Комплимент, выполняя этикетную функцию, ориентирован на неконфликтное общение, он социально задан и культурно закреплен (Вострикова, 2008).

4) Исходя из определения комплимента В. П. Шейнова, где говорится о том, что это «небольшое преувеличение достоинств человека, о которых ему приятно слышать» (Шейнов, 2015, с. 10), можно предположить, что одна из функций комплимента - доставление удоводьствия собеседнику. J. G. Loor проводил исследование комплиментов в цифровом пространстве и сделал вывод, что комплименты были направдены на то, чтобы «восхититься дичностью», тем самым доставдяя ей удоводьствие (Loor, 2020, с. 61). Удоводьствие сопровождается возникновением положительных эмоций, что тоже можно было бы выделить как отдельную функцию. Однако на наш взгляд, поднятие настроения в дюбом случае будет связано с доставлением удоводьствия.

5) Удовлетворение потребностей партнера в признании и одобрении. Делая компдименты другим, мы помогаем им чувствовать себя значимыми, вызывая при этом улыбку или приятное удивление. Исследователи D. C. Marigold, J. G. Holmes, M. Ross пытадись выявить связь уровня самооценки с принятием положительной обратной связи от романтических партнеров/супругов (Marigold et al., 2007). Посчитав, что люди с низкой самооценкой будут сопротивдяться добрым словам партнера по отношению к ним, авторы провели 3 исследования. Оказалось, что испытуемые с заниженной самооценкой чувствовади себя доводьно позитивно по отношению к высказыванию, к себе и к своему партнеру, когда выражали их значимость именно комплиментами - так же позитивно, как дюди с завышенной самооценкой. Иначе говоря, они демонстрировади принятие комплиментов, чувствуя себя ценными для своего партнера, что повышало их уровень удовлетворенности романтическими отношениями.

Кроме того, компдименты высоко ценятся в романтических отношениях обмен положительных эмоций и высказываний в форме комплимента является особенно ценным, иногда интимным ритуалом (Doohan, Manusov, 2004).

6) По мнению Е. С. Востриковой, следует выделить «созидательную (конструктивную) функцию комплимента в конфликтном дискурсе, которая проявляется, если в результате конфликта преодолеваются негативные или кризисные явления» (Вострикова, 2008, с. 98). Очень часто вовремя прозвучавший 
комплимент может повлиять на дальнейшую жизнь человека, успокоив строгого начальника или сохранив хорошие отношения с супругом, оставдяя стадию конфликта позади.

Представим ситуацию, где одна сотрудница пытается понизить авторитет другой всеми допустимыми способами по причине того, что она не хочет отдавать новой сотруднице свой заработанный тяжелым трудом статус лучшего работника - возникает конфликт. Осознав, что происходит между ними, новая сотрудница использует комплименты, чтобы настроить коллегу на нужный лад в разрешении возникшей ситуации, показав, что они не соперники, а партнеры, и должны в качестве стратегии избрать «сотрудничество».

7) Оказание психодогического воздействия так же является функцией комплимента, так как он вдияет на адресата, его эмоции, мысди и действия. Так, комплимент может выступать как способ осознаваемой или неосознаваемой манипуляции (Карташкова и др., 2017), как частный вид формирования благосклонности (Loor, 2020) и даже как самостоятельный вид психологического воздействия, имеющий свою структуру (Шейнов, 2015), в результате чего возникают как вербальные, так и невербальные ответы-реакции партнера.

Людям нравится видеть себя хорошими, достойными дюдьми. Партнер, который делает компдимент, удовлетворяет желание другого человека самосовершенствоваться и поэтому может восприниматься другим человеком как симпатичный и вызывающий доверие. Согласно Y. Dai, S. Y. Shin, N. Kashian, J. Jang, и J. B. Walther, даже людям, у которых отсутствует благоприятная самооценка и которые считают компдимент «неточным», тем не менее нравится человек, который делает им комплимент, и они хотят за это ему чем-то отплатить (Dai et al., 2016, p. 398).

N. K. Grant, L. R. Fabrigar и H. Lim было проведено два исследования, чтобы проверить вдияние комплиментов на уступчивость партнера и выяснить, может ли симпатия объяснить их эффективность. Оба исследования показали, что комплименты повышают уступчивость по сравнению с контродьным состоянием, при этом механизмы симпатии не явдяются необходимыми ддя того, чтобы комплименты усиливали уступчивость (Grant et al., 2010).

8) Альтернатива другим речевым актам. Комплимент может быть использован вместо других речевых актов. Это одна из причин, по которой компдименты могут появляться на любой стадии разговора. Большинство из них появляются в начале речи, что указывает на то, что комплимент может быть произнесен в качестве альтернативы приветствию (Cordella et al., 1995). Также он может использоваться как благодарность и извинение. Замена благодарности и извинения компдиментом предполагает, что люди осознают необходимость поощрения слушателя, например, за предыдущую услугу (в случае благодарности) или улучшения его настроения за прошлые или будущие оскорбления (извинения) (Cordella et al., 1995). 
Подводя итог, мы допускаем, что существуют и другие функции компдиментов в межличностном общении. Их выделение и изучение явится темой дальнейших исследований в данной области.

\section{Обсуждение резудьтатов}

Проведенный анализ позволяет выделить следующие направления исследований, по которым можно судить о значимости компдиментов в междичностном общении.

Первое направление связано с раздичными подходами к исследованию феномена комплимента: лингвистический, психологический и междисциплинарный подходы.

Второе направление раскрывает разнообразие комплиментов через его сравнение с лестью и похвалой. В работах данного направления выделяются цели и причины, по которым могут создаваться компдимент, лесть и похвала, раскрываются их сходства и раздичия.

Третье направление связано с вдиянием комплиментов на дадьнейшее развитие межличностных отношений. В таких исследованиях комплимент рассматривается как способ психологического воздействия на личность. Анализ исследований показал, что свидетельств негативного вдияния компдиментов недостаточно.

\section{Заключение}

На сегодняшний день комплимент явдяется самым действенным механизмом выстраивания отношений с положительным знаком, не считая улыбки и называние человека по имени. Важность комплиментов, которые умело составлены и поданы, высока, так как они открывают массу возможностей в раздичных отраслях человеческой деятельности и являются довольно функциональными.

В результате проведенного анализа отечественной и зарубежной дитературы по данной проблеме были сделаны следующие выводы.

Во-первых, компдимент представдяет собой высказывание, в котором отмечаются положительные стороны результата деятельности (физической или интелиектуальной) собеседника с целью сделать ему приятное и тем самым расположить его к себе (Беляева-Станден, 2006).

Во-вторых, исследования, посвященные анализу компдиментов, можно разделить на два вида: разграничивающие понятия «комплимент», «лесть» и «похвала» и объединяющие их в один речевой акт. На наш взгляд, компдимент не является суммой похвалы и лести, также и последние, в свою очередь, не являются его разновидностями. Комплимент, похвала и лесть раздичаются по целям, предмету и выборе позиции, однако, схожи в том, что могут вызвать положительную реакцию. 
В-третьих, анадиз проведенных исследований позводил выделить основные, на наш взгляд, функции комплимента. К ним относятся: 1) установление и поддержание доброжелательных отношений или гармонизация межличностных отношений; 2) оказание эмоционадьной поддержки; 3) соблюдение этикета; 4) доставление удовольствия собеседнику; 5) удовлетворение потребностей партнера в признании и одобрении; 6) конструктивная иди созидательная (в конфликтном дискурсе); 7) оказание психологического воздействия; 8) альтернатива другим речевым актам.

Тема комплиментов в науке еще недостаточно изучена, она требует дальнейшего рассмотрения и более углубленного анализа с точки зрения психологии. К примеру, еще не разработаны классификации комплиментов, которые бы раскрывали их психологическое содержание. Дальнейшие исследования, в том числе эмпирического характера, помогут уточнить выдвинутые нами предположения о функциях комплимента, выделить новые функции, более полно исследовать данный феномен.

\section{Автор заявляет об отсутствии конфдикта интересов}

\section{Дитература}

Арипова А. О., Крюкова Т. А. Эмоционадьная поддержка: о понятии и формах // Вестник Костромского государственного университета. Серия: Педагогика. Психология. Социокинетика. 2019. Т. 25, №2. С. 102-107. doi: 10.34216/2073-1426-2019-25-2-102-107

Бартош А. В., Нечаева Е. А. Комплимент как главное средство гармонизации межличностных отношений // Вестник гуманитарного факультета Ивановского государственного химико-технологического университета. 2008. №3. C. 139-147.

Беляева-Станден Е. И. Гендерные особенности компдимента россиян // Вопросы психолингвистики. 2006. №4. С. 155-170.

Вострикова Е. С. Функционирование компдимента в конфликтном дискурсе // Известия Российского государственного педагогического университета им. А. И. Герцена. 2008. № 83. С. 96-99.

Голубева А. Ф. Социально-психологические основы управления трудовым коллективом // Вестник ТГУ. Серия: Гуманитарные науки. 2015. №2 (142). С. 66-73.

Дьякова К. Ю. Компдимент как элемент речевого этикета в аспекте межкультурной коммуникации // Русистика. 2015. №1. С. 41-46.

Зимбардо, Ф., Аяйпnе, М. Социальное влияние: пер. с англ. СПб: Питер, 2001. 448 c.

Иссерс О. С. Коммуникативные стратегии и тактики русской речи. Изд. 5-е. М.: Издательство ЛКИ, 2008. 288 с. 
Карнеги Д. Как завоёвывать друзей и оказывать вдияние на дюдей. Минск: Попурри, 2020. 368 с.

Карташкова Ф. И., Мальцева Н. Б., Князева А. А. Компдимент как интенциональное состояние и как манипуяятивный прием // Вестник РУДН. Серия: Теория языка. Семиотика. Семантика. 2017. Т. 8, № 1. С. 106-114. doi: 10.22363/2313-2299-2017-8-1-106-114

Коваль Н. А., Захарова Е. А. Способы психологического воздействия на персонал // Вестник ТГУ. Серия: Гуманитарные науки. 2004. № 3. С. 37-40.

Разинов Ю. А. Социальный обмен иожью // Вестник Самарского государственного университета. 2014. Т. 20, № 5 (116). 20-24.

Саковская О. Н. Психология воздействия: практикум. Ярославль: ЯрГУ, 2017. 40 c.

Сидоренко Е. В. Аичностное вдияние и противостояние чужому вдиянию // Социальная психология в трудах отечественных психологов: СПб.: Питер, 2000. C. $148-170$.

Чалдини Р. Психология вдияния. 5-ое изд. СПб.: Питер, 2018. с. 336.

Шалюхина А. В. Комплимент и похвала как проявления эмпатии в испанском языке // Русистика. 2017. Т. 15, № 1. С. 91-102. doi:10.22363/2313-2264-2017-15-1-91-102

Шевчук Д. А. Деловое общение: Учебное пособие. Ростов-на-Дону: Феникс, 2006. 192 с.

Шейнов В. П. Неотразимый комплимент. Безотказные приемы вдияния. СПб.: Питер, 2015. 337 с.

Cordella M., Large H., Pardo V. Complimenting behavior in Australian English and Spanish speech // Multilingual. 1995. Vol. 14, Issue 3. P. 235-252. doi: $10.1515 /$ $\underline{\text { mult.1995.14.3.235 }}$

Dai Y., Shin S. Y., Kashian N., Jang J., Walther J. B. The Influence of Responses to SelfDisclosure on Liking in Computer-Mediated Communication // Journal of Language and Social Psychology. 2016. Vol. 35 Issue 4. P. 394-411. doi: $\underline{10.1177 / 0261927 X 15602515}$

Doohan E.-A. M., Manusov V. The communication of compliments in romantic relationships: An investigation of relational satisfaction and sex differences and similarities in compliment behavior // Western Journal of Communication. 2004. Vol. 68, Issue 2. P. 170-194. doi: 10.1080/10570310409374795

Grant N. K., Fabrigar L. R., Lim H. Exploring the Efficacy of Compliments as a Tactic for Securing Compliance, Basic and Applied Social Psychology. 2010. Vol. 32, Issue 3. P. 226-233. doi: 10.1080/01973533.2010.497456

Loor, J. G. The Compliment as a Social Strategy: a Discourse Analysis of On-line Compliments and Insults // Odisea. 2020. Issue 20. P. 35-64. doi: 10.25115/odisea. v0i20.2834

Marigold, D. C., Holmes, J. G., Ross, M. More than words: Reframing compliments from romantic partners fosters security in low self-esteem individuals. 
Journal of Personality and Social Psychology. 2007. Vol. 92 Issue 2. P. 232-248. doi: 10.1037/0022-3514.92.2.232

\section{References}

Aripova, A. O., \& Kryukova, T. L. (2019). Emotional support: the concept and forms. Vestnik of Kostroma state university. Series: Pedagogy. Psychology. Sociokinetics, 25(2), 102-107. doi: 10.34216/2073-1426-2019-25-2-102-107 (in Russ.).

Bartosh, A. V., \& Nechaeva, E. A. (2008). Compliment as the main means of harmonization of interpersonal relation. Vestnik of the Faculty of Humanities of the Ivanov State Chemical and Technology University, 3, 139-147. (in Russ.).

Beliaeva-Standen, E. I. (2006). Gender peculiarities of Russians' compliments. Journal of Psycholinguistics, 4, 155-170. (in Russ.).

Carnegie, D. (2020). How to Win Friends and Influence People. Minsk: Popurri. (in Russ.).

Cialdini, R. (2018). Psychology of Influence (5th ed.). St. Petersburg: Piter. (in Russ.).

Cordella, M., Large, H., \& Pardo, V. (1995). Complimenting behavior in Australian English and Spanish speech. Multilingual, 14(3), 235-252. doi: 10.1515/ $\underline{\text { mult.1995.14.3.235 }}$

Dai, Y., Shin, S. Y., Kashian, N., Jang, J., \& Walther, J. B. (2016). The Influence of Responses to Self-Disclosure on Liking in Computer-Mediated Communication. Journal of Language and Social Psychology, 35(4), 394-411. doi: 10.1177/0261927X15602515

Doohan, E.-A. M., \& Manusov, V. (2004). The communication of compliments in romantic relationships: An investigation of relational satisfaction and sex differences and similarities in compliment behavior, Western Journal of Communication, 68(2), 170-194. doi: 10.1080/10570310409374795

Dyakova, K. Y. (2015). Compliment as Element of Speech Etiquette in the Aspect of Intercultural Communication. Russian Language Studies, (1), 41-46. (in Russ.).

Golubeva, L. F. (2015). Social and psychological basics of management by working collective. Tambov University Review. Series: Humanities, 2(142), 66-73. (in Russ.).

Grant, N. K., Fabrigar, L. R., \& Lim, H. (2010). Exploring the Efficacy of Compliments as a Tactic for Securing Compliance, Basic and Applied Social Psychology, 32(3), 226-233. doi: 10.1080/01973533.2010.497456

Issers, O. S. (2008). Communication strategies and tactics of Russian speech (5th ed.). Moscow: LKI Publishing House. (in Russ.).

Kartashkova, F. I., Maltseva, N. B., \& Knyazeva, A. A. (2017). Compliment as intentional state and a manipulative device. RUDN Journal Of Language Studies, Semiotics And Semantics, 8(1), 106-114. doi: 10.22363/2313-2299-2017-8-1-106-114 (in Russ.).

Koval, N. A., \& Zakharova, E. A. (2004). Ways of influencing personnel psychologically. Tambov University Review. Series: Humanities, 3, 37-40. (in Russ.). 
Loor, J. G. (2020). The Compliment as a Social Strategy: a Discourse Analysis of On-line Compliments and Insults. Odisea, 20, 35-64. doi: 10.25115/odisea.v0i20.2834

Marigold, D. C., Holmes, J. G., \& Ross, M. (2007). More than words: Reframing compliments from romantic partners fosters security in low self-esteem individuals. Journal of Personality and Social Psychology, 92(2), 232-248. doi: 10.1037/0022-3514.92.2.232

Razinov, Y. A. (2014). Social exchange of lie. Vestnik of Samara state university, 5 (116), 20-24. (in Russ.).

Sakovskaja, O. N. (2017). Impact Psychology: Practicum. Yaroslavl: YarGU. (in Russ.).

Shalyukhina, A. V. (2017). Compliment and praise as manifestations of empathy in Spanish. Russian Language Studies, 15(1), 91-102. doi: 10.22363/2313-2264-201715-1-91-102 (in Russ.).

Sheinov, V. P. (2015). An irresistible compliment. Fail-safe methods of influence. St. Petersburg: Piter. (in Russ.).

Shevchuk, D. A (2006). Business communication: Training manual. Rostov-on-Don: Phoenix. (in Russ.).

Sidorenko, E. V. (2000). Personal influence and opposition to others' influence. In A. L. Svenzizki (Ed.), Social Psychology in the works of Russian psychologists (pp. 148170). St. Petersburg: Piter. (in Russ.).

Vostrikova, E. S. (2008). Functioning of a compliment in the conflict discourse. Izvestia: Herzen Leningrad State Pedagogical Institute, 38(82-1), 96-99. (in Russ.).

Zimbardo, P., \& Leippe, M. (2001). Social influence (Trans.). St. Petersburg: Piter. (in Russ.). 